\title{
Incomplete IUS removal
}

A 51-year-old woman was referred to my clinic to exchange her Mirena ${ }^{\circledR}$ intrauterine system (IUS). The IUS was inserted 8 years ago under local anaesthetic at the local hospital, as the general practitioner was unable to insert the IUS due to a tight cervix, as the woman's three births had all been by Caesarean section.

The patient was counselled and the IUS was removed and shown to her, however the transverse arms were missing (Figure 1). The arms were not seen in the cylinder on exploration.

A pelvic ultrasound scan revealed the presence of the IUS arms in the upper part of the uterus, and the patient was referred to a gynaecologist who performed a hysteroscopy but was unable to locate the IUS arms. The patient was rescanned, which once again showed the presence of the IUS arms in the upper part of the uterus (Figure 2).

The radiologist's comment was that the arms were not in the endometrial cavity, and there was what the radiologist called a linear echogenicity at the top end of the uterus under the surface lining of the uterus, which

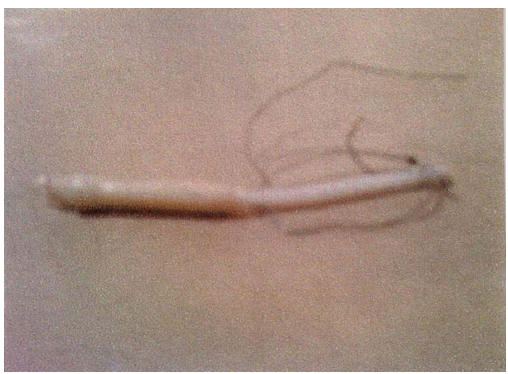

Figure 1 The intrauterine system following removal with the transverse arms missing. 


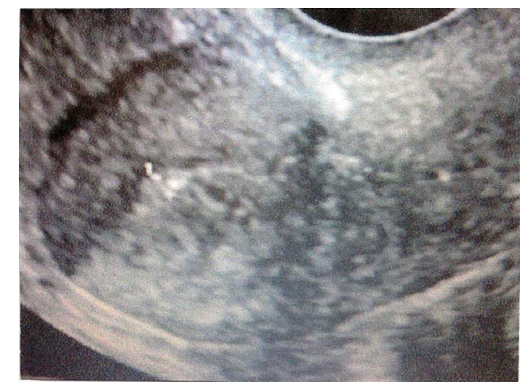

Figure 2 Pelvic ultrasound scan revealing the presence of the intrauterine system arms in the upper part of the uterus. were the IUS arms. An abdominal X-ray was proposed; however, the patient chose not to pursue the matter any further.

This type of problem has not been reported previously, and it may be observed more frequently, as an increasing number of IUS insertions are done in nulliparous women.

Vasantika Agarwal, DRCOG, DFSRH

Family Planning Trainer, Medical Centre, Rochester, UK; v.agarwal2@nhs.net
Competing interests None.

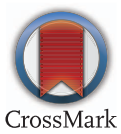

J Fam Plann Reprod Health Care 2014;40:235-236. doi:10.1136/jprhc-2014-100919

\section{Menopause Theory Course (FSRH Menopause Special Skills) \\ $6^{\text {th }} \& 7^{\text {th }}$ November $2014-13$ hours CME Holiday Inn Cardiff City Centre Castle Street, Cardiff, CF10 1XD}

This course is suitable for a doctor or nurse who is already providing women's health care whether in primary care, sexual health, community or acute gynaecology settings. This program will focus on the consensus view of the published evidence base and discuss how it can be applied to assist every day clinical practice. It is both pragmatic and practical in outlook. Course Fee $£ 395$ (not residential)

Further details and application form online at www.crescetis.co.uk

Mike Gray - Crescetis, Egloserme Farm, St Erme, Truro, Cornwall, TR4 9BW

Tel: 01872242192 - Email: info@crescetis.com

\section{Northern Interbranch Group}

Autumn Update on Saturday 11th October 2014 at The Source

Conference Centre, 300 Meadowhall Way, Sheffield S9 1EA

Provisional Programme includes:

Effects of contraceptive and HRT hormones on the cardiovascular system.

Management of sexual assault.

Child sexual exploitation and safeguarding issues.

Contraception and sexual health case studies.

Suitable for FSRH self certification for $\mathbf{4}$ hours CPD.

Contact for information and application form:-

Angela Walker

Angela.j.walker@btinternet.com 